\title{
Building Optimum Production Settings using De Novo Programming with Global Criterion Method
}

\author{
Nurullah Umarusman \\ Aksaray University,Faculity of \\ Economics\&Administrative \\ Sciences, Aksaray-Turkey
}

\author{
Ahmet Türkmen \\ Erciyes University, Faculity of \\ Economics\&Administrative \\ Sciences, Kayseri-Turkey
}

\begin{abstract}
This study consists of four main parts. In first part, a brief history of De Novo technique is introduced. In part two, mathematical definitions of Multicriteria De Novo Programming and Global Criterion Method are given with their respective principles. Part three shows a real firm application where the problem and solution parts are shown. Final part of the study concludes the study with explanations and future aims of the study group.
\end{abstract}

\section{General Terms}

De Novo Programming, Multicriteria Decision Making

\section{Keywords}

De Novo programming, Global Criterion Method, Optimal System Design.

\section{INTRODUCTION}

In mathematical techniques, aside objective functions, constraints affect the solution too. Where there are unused resources in a mathematical model, this causes objective functions occur in a lesser value. Thus, it is necessary to use the resources to their full aside the objective functions having the best values. Fully used constraints are named active constraints. In order to make a Linear Programming Problem an optimal one, all constraints have to be active constraints.Using De Novo assumption, it is possible to optimally use the constraints and the objective function takes the best possible value in accordance with directions of objective functions.

Multicriteria De Novo Programming was first studied by Zeleny [13]. According to De Novo assumption, it is possible to build an optimal model in accordance with a pre-defined budget and production means [15]. The most significant feature of the technique is that it creates an optimal system design, instead of optimizing the given system. System design is a process of creation, not selection, of alternatives [16]. The difference between an optimal system and optimizing a system is about using all the constraints to their full capacity [14]. De Novo formulation does not only deal with specifying the best mixture of output, but also with the best mixture of input too[11].

Having implied that Multicriteria De Novo Programming problems do not have a definitive solution technique, Zeleny [15] proposed a basic method to construct the optimal system design for solving a De Novo problem. Shi [9] defines six different types of optimum-path ratio. A new approach is also proposed for Multiobjective De Novo Programming [3]. Aside those solution types, fuzzy solutions are available too [7] bound to both positive and negative ideal solutions. Furthermore, Min-Max Goal Programming, bound to positive and negative ideal solutions, are used by Umarusman [12]. Babic and Pavic [1], Shi [10], Chen and Hsieh [5], Huang, et al. [6], Zhang et al. [17], and Chen and Tzeng [4] have contributed De Novo Programming literature with their studies.

\section{GLOBAL CRITERION METHOD FOR DE NOVO TECHNIQUE}

In this study, Global Criterion method is used for solving a Multicriteria De Novo Programming problem. Furthermore, traditional solution for De Novo assumption is also done and results are contrasted with the results obtained from Global Criterion method solution. In order to be able to compare the results under the same perception, " $p$ " is taken " 1 " $(p=1)$ to ensure the function is linear.

\subsection{Multicriteria De Novo Programming}

In this section, basic formulation of De Novo Programming, as defined by Zeleny [16], is shown. Formulation deals with both maximization and minimization type functions. Multicriteria De Novo Programming is mathematically composed as following:

$$
\begin{aligned}
& \operatorname{Max} Z_{k}=C^{1} x \\
& \operatorname{Min} W_{s}=C^{2} x
\end{aligned}
$$

Subject to

$$
\begin{aligned}
& A x-b \leq 0 \\
& p b \leq B \\
& x \geq 0,
\end{aligned}
$$

where $Z_{k}=C^{1} x=\sum_{j=1}^{n} c_{k j} x_{j}, \quad k=1,2, \ldots, l$, are $l$ objective functions $Z_{k}$ to be maximized simultaneously. $W_{s}=C^{2} x=$ $\sum_{j=1}^{n} c_{s j} x_{j}, s=1,2, \ldots r$, are $r$ objective functions $W_{s}$ to be minimized simultaneously. $\quad C^{1} \in \mathbb{R}^{l x n}, \quad C^{2} \in \mathbb{R}^{r x n}$ and $A \in \mathbb{R}^{m x n}$ are matrices of dimensions $l x n, \quad r x n$ and $m x n$ respectively. $b \in \mathbb{R}^{m}$ is the $m$-dimensional unknown resource vector, $p \in \mathbb{R}^{m}$ is the vector of unit prices of $m$ resources, and $B$ is the given total budget. Solution of (1) is redefined by the best feasible solution of each objective function under budget restriction and re-defined resources. Each resource's unit price is used for restructuring the problem as a "knapsack" problem:

$$
\begin{aligned}
& \operatorname{Max} Z_{k}=C^{1} x \\
& \operatorname{Min} W_{s}=C^{2} x
\end{aligned}
$$

Subject to

$$
\begin{aligned}
& V x \leq B \\
& x \geq 0,
\end{aligned}
$$

where $Z_{k}=\left(Z_{1}, \ldots, Z_{l}\right) \in \mathbb{R}^{l}, W_{s}=\left(W_{1}, \ldots, W_{r}\right) \in \mathbb{R}^{r}$ and $V=\left(V_{1}, \ldots, \ldots V_{n}\right)=p A \in \mathbb{R}^{n}$. Using the methodology of de novo single-criterion optimal, Problem (2) can be solved, for $x$ and $b$, with respect to each to objective functions $Z_{k}$ and $W_{s}$, 
respectively. Let vector $Z_{k}^{*}=\left(Z_{1}^{*}, \ldots, Z_{l}^{*}\right)$ and vector $W_{s}^{*}=$ $\left(W_{1}^{*}, \ldots, W_{r}^{*}\right)$ show the obtained ideal solutions under budget restriction. Obviously, $Z_{k}^{*}$ and $W_{s}^{*}$ must be attainable for a given budget level $B$.

\section{Min $V x$}

Subject to

$$
\begin{aligned}
& C^{1} x \leq Z_{k}^{*} \\
& C^{2} x \leq W_{s}^{*} \\
& x \geq 0,
\end{aligned}
$$

Solving (3) identifies the minimum budget $B^{*}$ at which the metaoptimum performance $Z_{k}^{*}$ and $W_{s}^{*}$ can be realized through $x^{*}$ and $b^{*}$. Solving problem (3) $B^{*}$ must exceed any given budget $B$. Optimum-path ration " $\mathrm{r}$ " can be used with a pre-defined budget "B":

$r=B / B^{*}$

Using " $r$ ", final solution formulations can be defined as: $x=r x^{*}, b=r b^{*}, Z=r Z_{k}^{*}$ ve $W=r W_{s}^{*}$

\subsection{The Global Criterion Method}

The Global Criterion Method measures the distance by using Minkowski's $L p$ metric. In this method, the aim is to minimize a function which defines a global criterion which is a measure of how close the decision maker can get to the ideal solution. Mathematical formulation is as follows [11].

$F(x)=\sum_{k=1}^{l}\left[\frac{Z_{k}\left(x^{*}\right)-Z_{k}(x)}{Z_{k}\left(x^{*}\right)}\right]^{p}$

Where $Z_{k}\left(x^{*}\right)$ is the value of objective function $l$ at its individual optimum $x^{*}, Z_{k}(x)$ is the function itself, $p(1 \leq$ $p \leq \infty)$ is integer valued exponent that serves to reflect the importance objectives. Boychuk and Ovchinnikov[2] suggest using $p=1$, whereas Salukvadze [8] suggests using $p=2$. Setting $p=1$ implies that equal importance is given to all deviations, while $p=2$ implies that these deviations are weighted proportionately with the largest deviations having the largest weight. Setting $p>2$ means that more and more weight is given to the largest of deviations. In addition, where $p=1$ (1.1) function is linear, whereas $p=2$ makes it a nonlinear function [11]. In order to keep the function linear, $p$ value is taken 1. Global Criterion Method for minimization objectives can be composed as following:

$\sum_{S=1}^{r}\left[\frac{W_{s}(x)-W_{s}\left(x^{*}\right)}{W_{s}\left(x^{*}\right)}\right]^{p}$

Taking (5) and (6) under consideration together, maximization and minimization objectives can be written as following:

$F(x)=\sum_{k=1}^{l}\left[\frac{Z_{k}\left(x^{*}\right)-Z_{k}(x)}{Z_{k}\left(x^{*}\right)}\right]^{p}+\sum_{s=1}^{r}\left[\frac{W_{s}(x)-W_{s}\left(x^{*}\right)}{W_{s}\left(x^{*}\right)}\right]^{p}(7)$

Using the constraints of (1) and using (7), the following proposed model can be used for solving the De Novo problem bound to Global Criterion Method:

$\operatorname{Min} G=\sum_{k=1}^{l}\left[\frac{Z_{k}\left(x^{*}\right)-Z_{k}(x)}{Z_{k}\left(x^{*}\right)}\right]^{p}+\sum_{s=1}^{r}\left[\frac{W_{s}(x)-W_{s}\left(x^{*}\right)}{W_{s}\left(x^{*}\right)}\right]^{p}$
Subject to

$$
\begin{aligned}
& A x-b \leq 0 \\
& p b \leq B \\
& x \geq 0,
\end{aligned}
$$

where, $Z_{k}=\left(Z_{1}, \ldots, Z_{l}\right) \in \mathbb{R}^{l}, W_{s}=\left(W_{1}, \ldots, W_{r}\right) \in \mathbb{R}^{r}$ and $V=\left(V_{1}, \ldots, . V_{n}\right)=p A \in \mathbb{R}^{n}, A \in \mathbb{R}^{m x n}$ is matrices of dimension $m x n, b \in \mathbb{R}^{m}$ is the $m$-dimensional unknown resource vector, $p \in \mathbb{R}^{m}$ is the vector of unit prices of $m$ resources, and $B$ is the given total budget.

\section{ILLUSTRATIVE EXAMPLE}

A production facility that produces four different types of plastic balls is taken for illustrating the problem. Use of raw materials and stock level are given in Table 1. The organization has a monthly budget of $\$ 8610$ for given materials. Aside with raw material usage constraints, the firm management dictate some additional constraints to both protect the products' visibility in the market and meet the forecasted market demand:

Table 1. Unists of Raw Material to be Used and Unit Prices

\begin{tabular}{|l|l|l|l|l|l|l|}
\hline $\begin{array}{l}\text { Raw } \\
\text { Materials }\end{array}$ & $\begin{array}{l}\text { PB1 } \\
(75 g r)\end{array}$ & $\begin{array}{l}\text { PB2 } \\
(90 \mathrm{gr})\end{array}$ & $\begin{array}{l}\text { PB3 } \\
(125 \mathrm{gr})\end{array}$ & $\begin{array}{l}\text { PB4 } \\
(150 \mathrm{gr})\end{array}$ & $\begin{array}{l}\text { Units } \\
\text { in } \\
\text { Stock }\end{array}$ & $\begin{array}{l}\text { Unit } \\
\text { Price } \\
(\$ / \mathrm{kg})\end{array}$ \\
\hline $\begin{array}{l}\text { PVC } \\
(\mathrm{kg})\end{array}$ & 33 & 40 & 58 & 66 & 1000 & 5,3 \\
\hline $\begin{array}{l}\text { DOP } \\
(\mathrm{kg})\end{array}$ & 32 & 38 & 56 & 64 & 1000 & 3,2 \\
\hline $\begin{array}{l}\text { Paint } \\
(\mathrm{kg})\end{array}$ & 5 & 6 & 8 & 10 & 100 & 0,6 \\
\hline $\begin{array}{l}\text { Wax } \\
(\mathrm{kg})\end{array}$ & 4 & 5 & 7 & 8 & 100 & 0,5 \\
\hline
\end{tabular}

$\left(P B_{1}+P B_{4}\right)-\left(P B_{2}+P B_{3}\right) \leq 2050$,

$P B_{1} \geq 3000, P B_{2} \leq 2000, P B_{3} \leq 3000$,

$P B_{4} \geq 3500, P B_{2}+P B_{3} \geq 4000$.

Aside with raw material and production constraints, firm management also define income, unit production and cost constraints. For income maximization, each plastic ball provide respectively $(1.3 ; 1.4 ; 1.85 ; 3.2)$, for cost minimization constraint, the respective values are $(0.6 ; 0.75 ; 1.1 ; 1.23)$, and for total unit production, values are $(1 ; 1 ; 1 ; 1)$. The MultiFunctional Linear Programming problem under those constraints occurs as following:

$\operatorname{Max} Z_{1}=1.3 P B_{1}+1.42 P B_{2}+1.85 P B_{3}+3.2 P B_{4}$

$\operatorname{Max} Z_{2}=P B_{1}+P B_{2}+P B_{3}+P B_{4}$

Min $W_{1}=0.6 P B_{1}+0.75 P B_{2}+1.1 P B_{3}+1.23 P B_{4}$

Subject to;

$0.033 P B_{1}+0.04 P B_{2}+0.058 P B_{3}+0.066 P B_{4} \leq 1000$

$0.032 P B_{1}+0.038 P B_{2}+0.056 P B_{3}+0.064 P B_{4} \leq 1000$

$0.005 P B_{1}+0.006 P B_{2}+0.008 P B_{3}+0.01 P B_{4} \leq 100$

$0.004 P B_{1}+0.005 P B_{2}+0.007 P B_{3}+0.008 P B_{4} \leq 100$

$\left(P B_{1}+P B_{4}\right)-\left(P B_{2}+P B_{3}\right) \leq 2050 P B_{1} \geq 3000 ;$

$P B_{2} \leq 2000 ; P B_{3} \leq 3500 ; P B_{4} \geq 3500$

$P B_{2}+P B_{3} \geq 4000$

$P B_{1}, P B_{2}, P B_{3}, P B_{4} \geq 0$ and integer. 
In order to be able to solve (P1) with De Novo, the problem is re allocated with (1).

$\operatorname{Max} Z_{1}=1.3 P B_{1}+.42 P B_{2}+1.85 P B_{3}+.2 P B_{4}$

$\operatorname{Max} Z_{2}=P B_{1}+P B_{2}+P B_{3}+P B_{4}$

Min $W_{1}=0.6 P B_{1}+0.75 P B_{2}+1.1 P B_{3}+1.23 P B_{4}$

Subject to;

$0.033 P B_{1}+0.04 P B_{2}+0.058 P B_{3}+0.066 P B_{4}-b_{1} \leq 0$

$0.032 P B_{1}+0.038 P B_{2}+0.056 P B_{3}+0.064 P B_{4}-b_{2} \leq 0$

$0.005 P B_{1}+0.006 P B_{2}+0.008 P B_{3}+0.01 P B_{4}-b_{3} \leq 0$

$0.004 P B_{1}+0.005 P B_{2}+0.007 P B_{3}+0.008 P B_{4}-b_{4} \leq 0$

$4.3 b_{1}+3.2 b_{2}+0.6 b_{3}+0.5 b_{4} \leq 8610$

$\left(P B_{1}+P B_{4}\right)-\left(P B_{2}+P B_{3}\right) \leq 2050$

$P B_{1} \geq 3000$

$P B_{2} \leq 2000$

$P B_{3} \leq 3500$

$P B_{4} \geq 3500$

$P B_{2}+P B_{3} \geq 4000$

$P B_{1}, P B_{2}, P B_{3}, P B_{4}, b_{1}, b_{2}, b_{3}, b_{4} \geq 0$ and integer.

(P2) solution is conducted by using (1)-(4) for traditional De Novo. (1) or (2) can be used for determining each objective function. Ideal solutions for each objective occur as following:

$Z_{1}^{*}=27674,03 ; P B_{1}=3000 ; P B_{2}=2000 ;$

$P B_{3}=3500 ; P B_{4}=4550$

$Z_{2}^{*}=13050 ; P B_{1}=3000 ; P B_{2}=2000$;

$P B_{3}=3500 ; P B_{4}=4550$

$W_{1}^{*}=10300 ; P B_{1}=3000 ; P B_{2}=2000$;

$P B_{3}=2450 ; P B_{4}=3500$

Clearly each objective is realized in different variable values

Table 2 shows the meta-optimums using (3).

Table 2. Meta-optimum solutions

\begin{tabular}{|c|r|r|r|}
\hline Variables & \multicolumn{1}{|c|}{$Z_{1}$} & \multicolumn{1}{|c|}{$Z_{2}$} & \multicolumn{1}{c|}{$W_{1}$} \\
\hline$P B_{1}$ & 3000 & 3000 & 3000 \\
\hline$P B_{2}$ & 2000 & 2000 & 2000 \\
\hline$P B_{3}$ & 3500 & 3500 & 3500 \\
\hline$P B_{4}$ & 4550 & 4550 & 4550 \\
\hline$b_{1}$ & 659.2 & 659.2 & 659.2 \\
\hline$b_{2}$ & 682.3 & 682.3 & 682.3 \\
\hline$b_{3}$ & 100.5 & 100.5 & 100.5 \\
\hline$b_{4}$ & 82,9 & 82.9 & 82.9 \\
\hline $\begin{array}{l}\text { Objective Function } \\
\text { Values }\end{array}$ & 27775 & 13050 & 12746.5 \\
\hline
\end{tabular}

Variables that are determined by using De Novo in Table 2 is to be taken under with a budget of $\$ 5119,670$. Since $\$ 5119.670 \leq \$ 8610$, there is no need to determine an optimum path ratio.

Global Criterion method puts objective functions of (P2) by using (7) as following:

Min $G=1-\left[0.0000652 P B_{1}+0.0000549 P B_{2}\right.$

$$
\left.+0.0000364 P B_{3}+0.0000724 P B_{4}\right]
$$

Based on this allocation, with use of (8), De Novo Problem solution Global model is as follows:

$$
\begin{aligned}
\operatorname{Max} G= & 0.0000652 P B_{1}+0.0000549 P B_{2} \\
& +0.0000364 P B_{3}+0.0000724 P B_{4}
\end{aligned}
$$

Subject to

$0,033 P B_{1}+0,04 P B_{2}+0,058 P B_{3}+0,066 P B_{4}-b_{1} \leq 0$

$0,032 P B_{1}+0,038 P B_{2}+0,056 P B_{3}+0,064 P B_{4}-b_{2} \leq 0$

$0,005 P B_{1}+0,006 P B_{2}+0,008 P B_{3}+0,01 P B_{4}-b_{3} \leq 0$

$0,004 P B_{1}+0,005 P B_{2}+0,007 P B_{3}+0,008 P B_{4}-b_{4} \leq 0$

$4,3 b_{1}+3,2 b_{2}+0,6 b_{3}+0,5 b_{4} \leq 8610$

$\left(P B_{1}+P B_{4}\right)-\left(P B_{2}+P B_{3}\right) \leq 2050$

$P B_{1} \geq 3000$

$P B_{2} \leq 2000$

$P B_{3} \leq 3500$

$P B_{4} \geq 3500$

$P B_{2}+P B_{3} \geq 4000$

$P B_{1}, P B_{2}, P B_{3}, P B_{4}, b_{1}, b_{2}, b_{3}, b_{4} \geq 0$ and integer.

Determined objective function values with (P3) solution occur as: $x^{*}=(3000 ; 2000 ; 3500 ; 4550)$. The calculated budget determined by given variables is $\$ 5119,670$. All calculations

\begin{tabular}{|c|c|c|c|c|c|c|}
\hline \multirow[t]{2}{*}{ Variables } & \multicolumn{3}{|c|}{$\begin{array}{l}\text { De Novo } \\
\text { Solution }\end{array}$} & \multicolumn{3}{|c|}{$\begin{array}{l}\text { Global Criterion } \\
\text { Solution }\end{array}$} \\
\hline & $Z_{1}$ & $Z_{2}$ & $W_{1}$ & $Z_{1}$ & $Z_{2}$ & $W_{1}$ \\
\hline$P B_{1}$ & \multicolumn{3}{|c|}{3000} & \multicolumn{3}{|c|}{3000} \\
\hline$P B_{2}$ & \multicolumn{3}{|c|}{2000} & \multicolumn{3}{|c|}{2000} \\
\hline$P B_{3}$ & \multicolumn{3}{|c|}{3500} & \multicolumn{3}{|c|}{3500} \\
\hline$P B_{4}$ & \multicolumn{3}{|c|}{4550} & \multicolumn{3}{|c|}{4550} \\
\hline & $Z_{1}$ & \multicolumn{2}{|c|}{27775} & $Z_{1}$ & \multicolumn{2}{|c|}{27775} \\
\hline & $Z_{2}$ & \multicolumn{2}{|c|}{13050} & $Z_{2}$ & \multicolumn{2}{|c|}{13050} \\
\hline & $W_{1}$ & \multicolumn{2}{|c|}{12746,5} & $W_{1}$ & \multicolumn{2}{|c|}{12746,5} \\
\hline
\end{tabular}
are given in Table 3 for illustrating a general summary.

Table 3. Summary

De Novo solution suggestion and Global solution suggestion are seen on the same variable values in Table 3 . In Table 4, intial resource values, model suggested values and required budgets are given.

Table 4. Use of Capacity Values

\begin{tabular}{|c|c|c|c|}
\hline Resources & Initial & $\begin{array}{c}\text { De Novo } \\
\text { Suggestion }\end{array}$ & $\begin{array}{c}\text { Global } \\
\text { Criterion } \\
\text { Suggestion }\end{array}$ \\
\hline$b_{1}$ & 1000 & 659.2 & 659.2 \\
\hline$b_{2}$ & 1000 & 682.3 & 682.3 \\
\hline$b_{3}$ & 100 & 100.5 & 100.5 \\
\hline$b_{4}$ & 100 & 82.9 & 82.9 \\
\hline Budget $(\$)$ & 8610 & 5119.670 & 5119.670 \\
\hline
\end{tabular}

Inspecting Table 3 and Table 4, it is clear that suggested values of budgets by solutions are lesser from the initial budget. Taking budget in consideration only, there is a $\$ 3470,33$ reduction in subject value where all three objective functions are optimally satisfied. In addition, comparing (P2) objective function ideal solutions with meta-optimum and global solutions, ideal solution of all objective functions are 
satisfied on the $Z_{1}$ and $Z_{2}$, with same values whereas an increase is observed in $W_{1}$. This is a well calculated and expected situation. Goals of meta-optimum and global solutions together reach an optimal solution where all resources are fully used. Because of the characteristics of De Novo assumption, for (P2), ideal solutions for $Z_{1}$ and $Z_{2}$ occur on same values whereas $W_{1}$ occurs on different values. Meta-optimum solution enables all 3 objectives to be solved on the same value. Consequently, an increase in $W_{1}$ is unavoidable. Global method's result with $\mathrm{p}=1$ shows that the solution is to occur on either of $Z_{1}, Z_{2}, W_{1}$ points. Because Global solution is conducted with $\operatorname{Min} G=1-$ $\left[0.0000652 P B_{1}+0.0000549 P B_{2}+0.0000364 P B_{3}+\right.$ $0.0000724 P B_{4}$ ] equation, $(\mathrm{P} 3)$ solution value is 0,56662 with given constraints. As a result, De Novo solution and Global solution both suggest that problem result should occur on the same value.

\section{CONCLUSION}

As explained in previous sections, budget given for the same level of production is significantly reduced by an improvement in problem constraints. It can be seen that both Global Criterion Method and simple De Novo solutions give the same values. However, eventhough it is no coincidence, this situation is merely a result of the problem design. Optimum solution occurs in first two objective functions for both methods, which results to return of the same value in final calculations. Our study group is aiming to continue studying multicriteria De Novo Programming with and without under Global Criterion Method in future.

\section{REFERENCES}

[1] Babić, Z., and Pavić, I., 1996, Multicriterial Production Programming by De Novo Programming Approach, International Journal of Production Economics, 43(1), 59-66.

[2] Boychuk, L. and Ovchinnikov, V.,1973, Principal methods of solution of multicriterial optimization problems. Soviet Automatic Control, 6,1-4.

[3] Chakraborty, S. and Bhattacharya, D., 2013, Optimal System Design Under Multi-Objective Decision Making Using De-Novo Concept: A New Approach, International Journal Of Computer Applications , Volume 63- No.12, 0975 - 8887.

[4] Chen, J.K.C. and Tzeng, G-H.,2009, Perspective strategic alliances and resource allocation in supply chain systemsthrough the De Novo programming approach. Int. J. Sustainable Strategic Management, 1(3),320-339.
[5] Chen, Y-W. and Hsieh, H.-E.,2006,. Fuzzy multi-stage De-Novo programming problem. Applied Mathematics and Computation 181(2), 1139-1147.

[6] Huang, J.-J., Tzeng, G-H. and Ong, C.-S. ,2006, Choosing best alliance partners and allocating optimal alliance resources using the fuzzy multi-objective dummy programming model. Journal of the Operational Research Society 57, 1216-1223.

[7] Li, R.J and Lee, E.S.,1990, Approaches To Multicriteria De Novo Programs, Journal of Mathematical Analysis and Applications 153, 97-111.

[8] Salukvadze, M., 1974, On the existence of solution in problems of optimization under vector valued criteria. Journal of Optimization Theory and Applications, 12(2),203-217.

[9] Shi, Y.,1995, Studuies on optimum-Path Ratios in Multicriteria De Novo Programming Problems, Computers Math. Applic. Vol 29, No.5, 43-50.

[10] Shi, Y.,1999, Oprimal System Design With Multiple Decision Makers And Possible Debt: A Multicriteria De Novo Programming Approach, Operations Research Vol.47, No. 5, September-October,723-729.

[11] Tabucanon,M.T., 1988, Multiple Criteria Decision Making, Elsevier, Amsterdam.

[12] Umarusman, N., 2013, Min-Max Goal Programming Approach For Solving Multi-Objective De Novo Programming Problems, International Journal of Operations ResearchVol. 10, No. 2, 92-99.

[13] Zeleny, M.,1976,Multi-objective design of highproductivity systems, In: Proc. Joint Automatic Control Conf., paper APPL9-4, New York.

[14] Zeleny M.,1982, Multiple Criteria Decision Making. McGraw-Hill, New York.

[15] Zeleny, 1986, Optimal system design with multiple criteria: De Novo programming approach, Engineering Costs and Production Economics, 10,89-94.

[16] Zeleny M., 1990, Optimizing Given Systems Vs. Designing Optimal Systems: The De Novo Programming Approach, İnt. J. General System Vol 17,295-307.

[17] Zhang, Y.M., Huang, G.H. and Zhang, X.D. (2009). Inexact de Novo programming for water resources systemsplanning. European Journal of Operational Research, 199,531-541. 